\title{
Selective Shortening of Single-Crystalline Gold Nanorods by Mild Oxidation
}

Chia-Kuang Tsung, Xiaoshan Kou, Qihui Shi, Jinping Zhang, Man Hau Yeung, Jianfang Wang, and Galen D. Stucky

Department of Chemistry and Biochemistry, University of California, Santa Barbara, California 93106, and Department of Physics, the Chinese University of Hong Kong, Shatin, New Territories, Hong Kong, P. R. China

\section{Supporting Information}

\section{Synthesis of starting gold nanorods}

Starting gold nanorods (NRs) were synthesized using the silver ion-assisted seed-mediated method, as described previously. ${ }^{6}$ Briefly, to first prepare a solution of spherical Au nanoparticle seeds, $0.25 \mathrm{~mL}$ of an aqueous $0.01 \mathrm{M}$ solution of $\mathrm{HAuCl}_{4} \cdot 3 \mathrm{H}_{2} \mathrm{O}$ was added into $7.5 \mathrm{~mL}$ of an aqueous $0.1 \mathrm{M}$ cetyltrimethylammonium bromide (CTAB) solution in a plastic test tube. The solution was gently mixed by inversion. Then, $0.6 \mathrm{~mL}$ of an aqueous $0.01 \mathrm{M}$ ice-cold $\mathrm{NaBH}_{4}$ solution was added all at once, followed by rapid inversion mixing for $2 \mathrm{~min}$. The seed solution was kept in a water bath at $25^{\circ} \mathrm{C}$ and was used at least $2 \mathrm{~h}$ after its preparation. To grow Au NRs, 0.6 $\mathrm{mL}$ of $0.01 \mathrm{M} \mathrm{HAuCl}_{4} \cdot 3 \mathrm{H}_{2} \mathrm{O}$ and $0.09 \mathrm{~mL}$ of $0.01 \mathrm{M} \mathrm{AgNO}_{3}$ were added into $14.25 \mathrm{~mL}$ of $0.1 \mathrm{M}$ CTAB in a plastic test tube, followed by gentle inversion mixing. $0.096 \mathrm{~mL}$ of $0.1 \mathrm{M}$ ascorbic acid solution was then added and the resulting solution was mixed. Finally, $0.063 \mathrm{~mL}$ of the seed solution was added, the reaction mixture was gently mixed for $10 \mathrm{~s}$, and then left undisturbed for at least $3 \mathrm{~h}$.

The molar amount of silver ions is $15 \mathrm{~mol} \%$ of that of gold salt in the growth solutions of $\mathrm{Au}$ NRs. Previous measurements using energy-dispersive X-ray analysis (EDXA) ${ }^{6 \mathrm{~b}}$ and inductively coupled plasma (ICP) atomic emission spectrometry ${ }^{6 c}$ have indicated that less than $5 \%$ of the initial silver ions in the growth solution is associated with Au NRs and that the silver content in each $\mathrm{Au}$ $\mathrm{NR}$ is $2.5-4.5 \mathrm{~mol} \%$. We also carried out EDAX measurements on individual Au NRs, trying to find out whether silver is adsorbed on the surface of Au NRs or incorporated uniformly within Au NRs. However, Ag was barely detected on individual Au NRs, including as-synthesized and shortened ones, which suggests that the amount of Ag associated with individual Au NRs is close to the detection limit of our EDAX system. If we assume a gold nanorod 15-nm wide and 40-nm long contains $4 \mathrm{~mol} \%$ of silver, the total amount of silver present will be $3 \times 10^{-18} \mathrm{~g}$. 


\section{Standard reduction potentials of some related half reactions}

\begin{tabular}{c|c}
\hline Half reaction & Standard reduction potential $\left(E^{\circ}\right)$ \\
\hline $\mathrm{O}_{2}+4 \mathrm{H}^{+}+4 \mathrm{e} \rightarrow 2 \mathrm{H}_{2} \mathrm{O}$ & $1.229 \mathrm{~V}$ \\
$\mathrm{AuBr}_{2}^{-}+\mathrm{e} \rightarrow \mathrm{Au}+2 \mathrm{Br}^{-}$ & $0.959 \mathrm{~V}$ \\
$\mathrm{AuBr}_{4}{ }^{-}+3 \mathrm{e} \rightarrow \mathrm{Au}+4 \mathrm{Br}^{-}$ & $0.854 \mathrm{~V}$ \\
$\mathrm{AuCl}_{4}{ }^{-}+3 \mathrm{e} \rightarrow \mathrm{Au}+4 \mathrm{Cl}^{-}$ & $1.002 \mathrm{~V}$ \\
$\mathrm{H}_{2} \mathrm{O}_{2}+2 \mathrm{H}^{+}+2 \mathrm{e} \rightarrow 2 \mathrm{H}_{2} \mathrm{O}$ & $1.776 \mathrm{~V}$ \\
\hline
\end{tabular}

From "Electrochemical Series", in CRC Handbook of Chemistry and Physics, Internet Version 2005; Lide, D. R., Ed.; <http://www.hbcpnetbase.com>; CRC Press: Boca Raton, FL, 2005.

a)
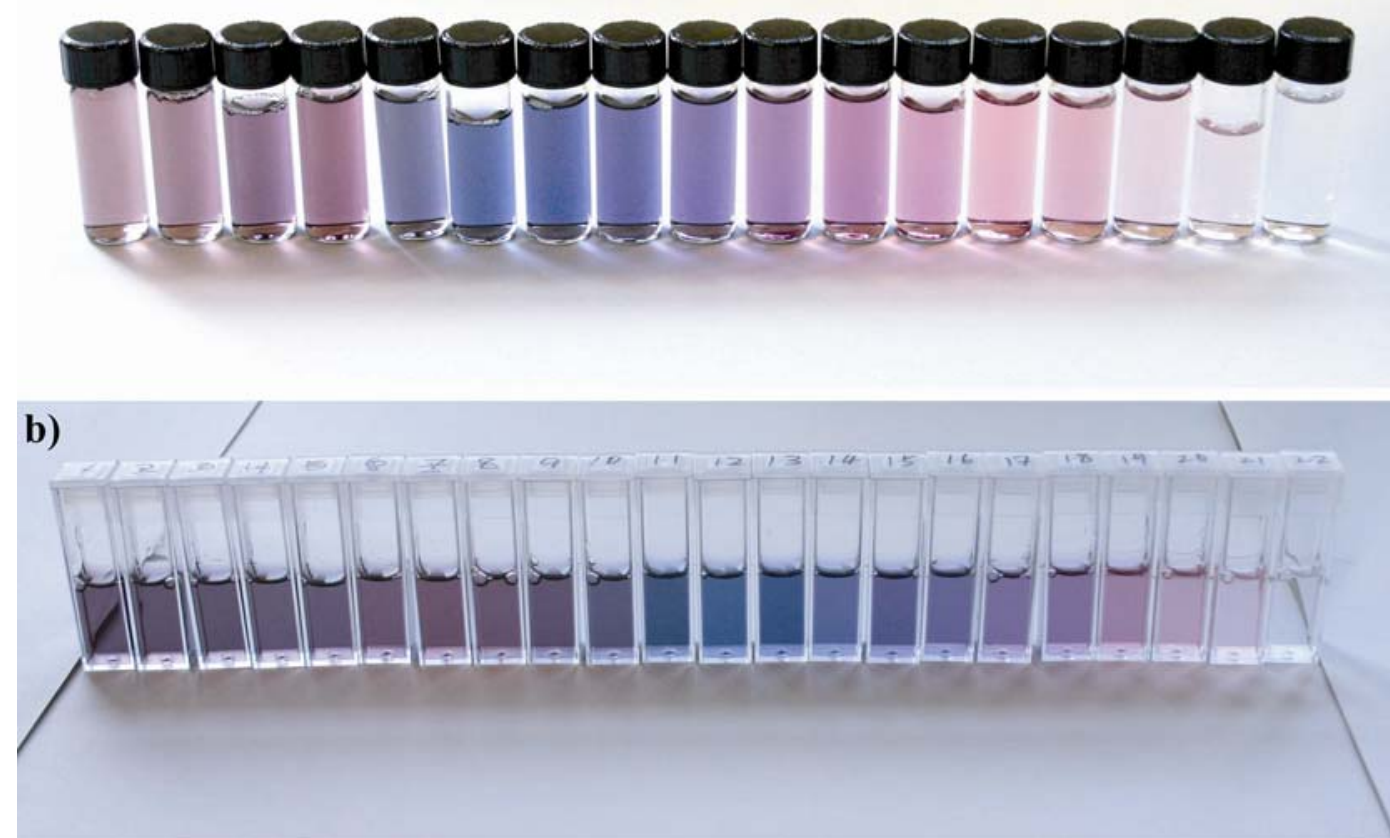

Figure S1. Digital pictures of the samples taken out after varying oxidation time. (a) In vials. (b) In cells for measuring UV-Visible extinction spectra. The initial solution shown in the leftmost side is a mixture of as-synthesized $\mathrm{Au} \mathrm{NR}$ solution and $1 \mathrm{M} \mathrm{HCl}$ at a volume ratio of 1.0. The oxidation temperature was at $70{ }^{\circ} \mathrm{C}$. The clear and colorless solution at the rightmost side is the sample after the complete oxidation of Au nanoparticles. The samples shown in both pictures are aligned from the left to right side in the order of increasing oxidation time. 

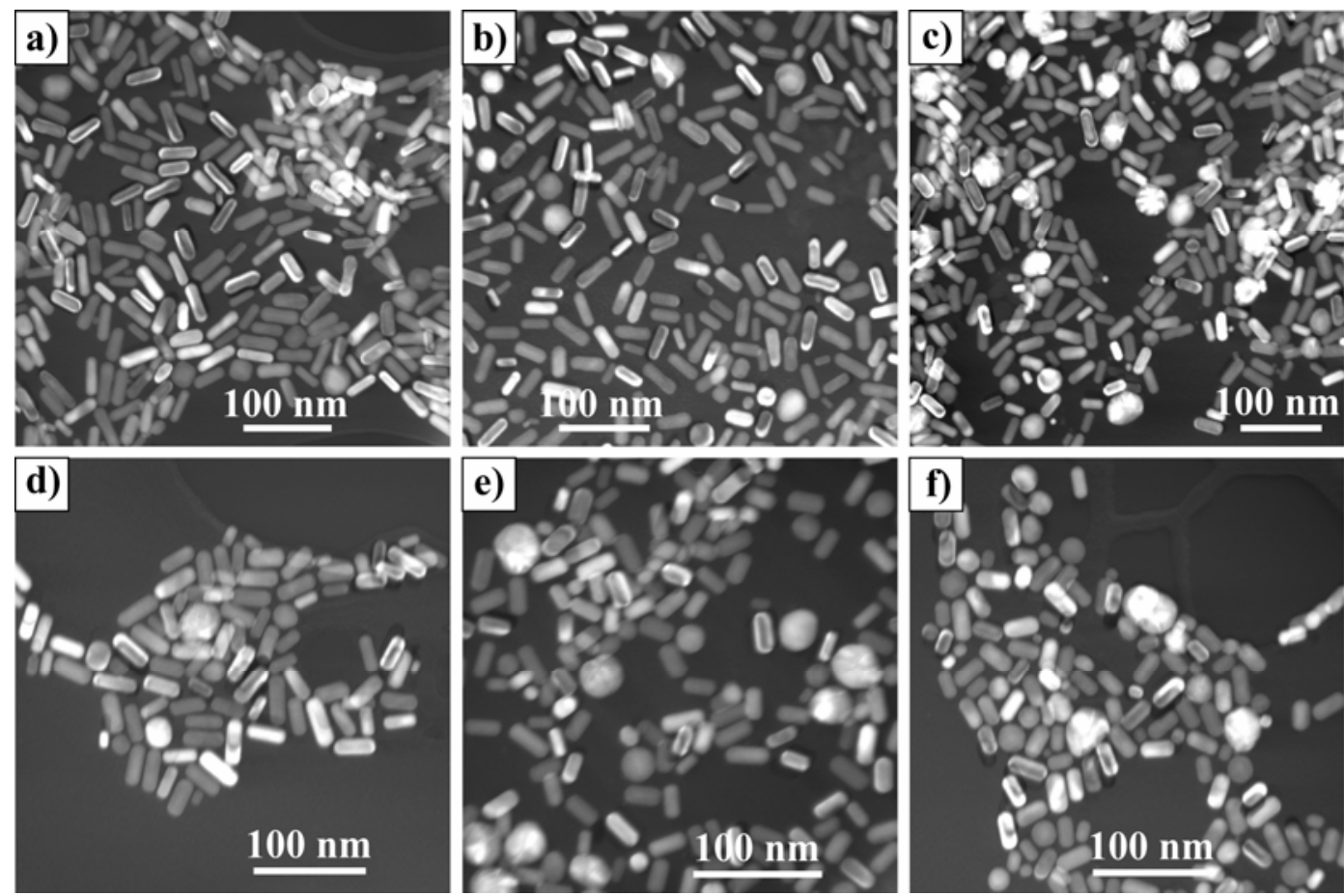

Figure S2. TEM images of Au NR samples obtained after varying oxidation time. (a) Au NRs with an average diameter of 13 (2) nm, an average length of 38 (5) nm, an average aspect ratio of 3.1 (5), and the longitudinal plasmon wavelength (LPW) at $700 \mathrm{~nm}$. (b) Au NRs with an average diameter of 13 (2) nm, an average length of 37 (4) nm, an average aspect ratio of 2.9 (4), and the LPW at 683 $\mathrm{nm}$. (c) Au NRs with an average diameter of 13 (2) nm, an average length of 34 (5) nm, an average aspect ratio of 2.6 (4), and the LPW at $663 \mathrm{~nm}$. (d) Au NRs with an average diameter of 13 (2) nm, an average length of $33(5) \mathrm{nm}$, an average aspect ratio of 2.5 (3), and the LPW at $658 \mathrm{~nm}$. (e) Au NRs with an average diameter of $12(2) \mathrm{nm}$, an average length of $27(4) \mathrm{nm}$, an average aspect ratio of 2.2 (3), and the LPW at $620 \mathrm{~nm}$. (f) Au NRs with an average diameter of 13 (2) nm, an average length of 28 (3) nm, an average aspect ratio of 2.1 (2), and the LPW at $616 \mathrm{~nm}$. The numbers in the parentheses indicate the uncertainties in the last digits. 

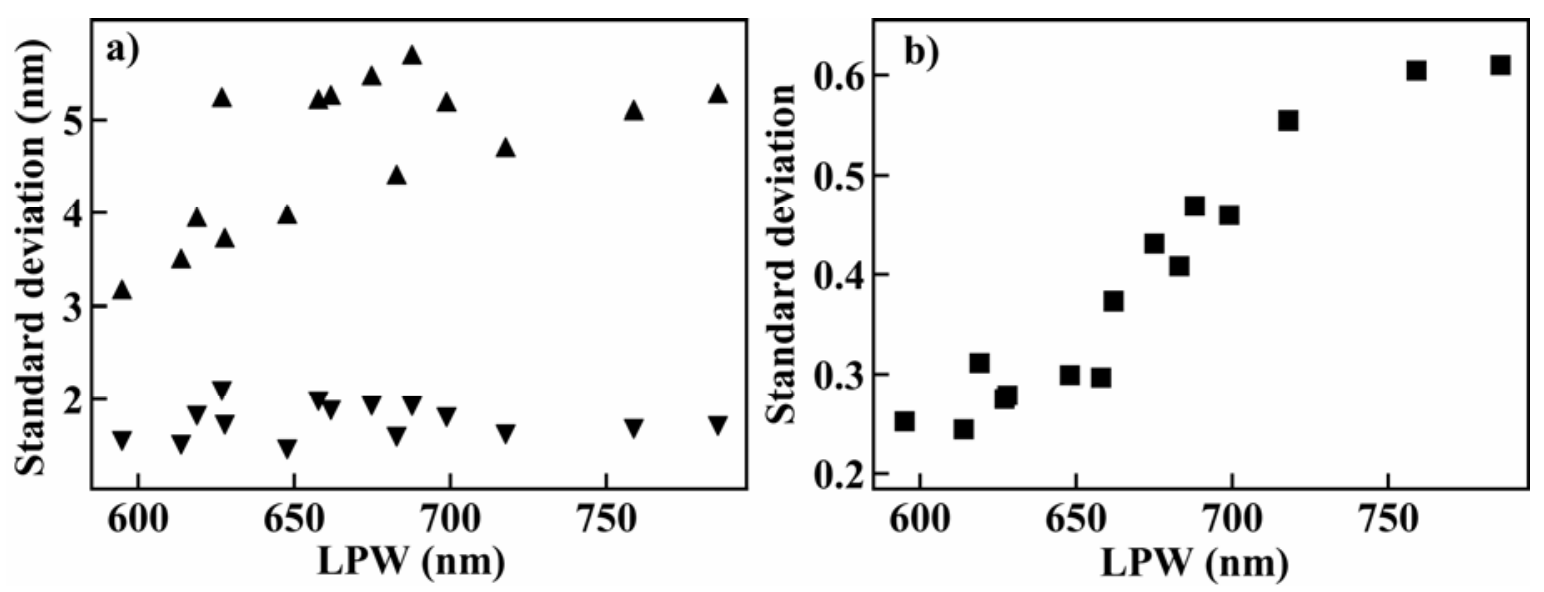

Figure S3. (a) Standard deviations in lengths (upward triangles) and diameters (downward triangles) of Au NRs obtained after varying oxidation time. (b) Standard deviation in aspect ratios (squares) of Au NRs obtained after varying oxidation time. 

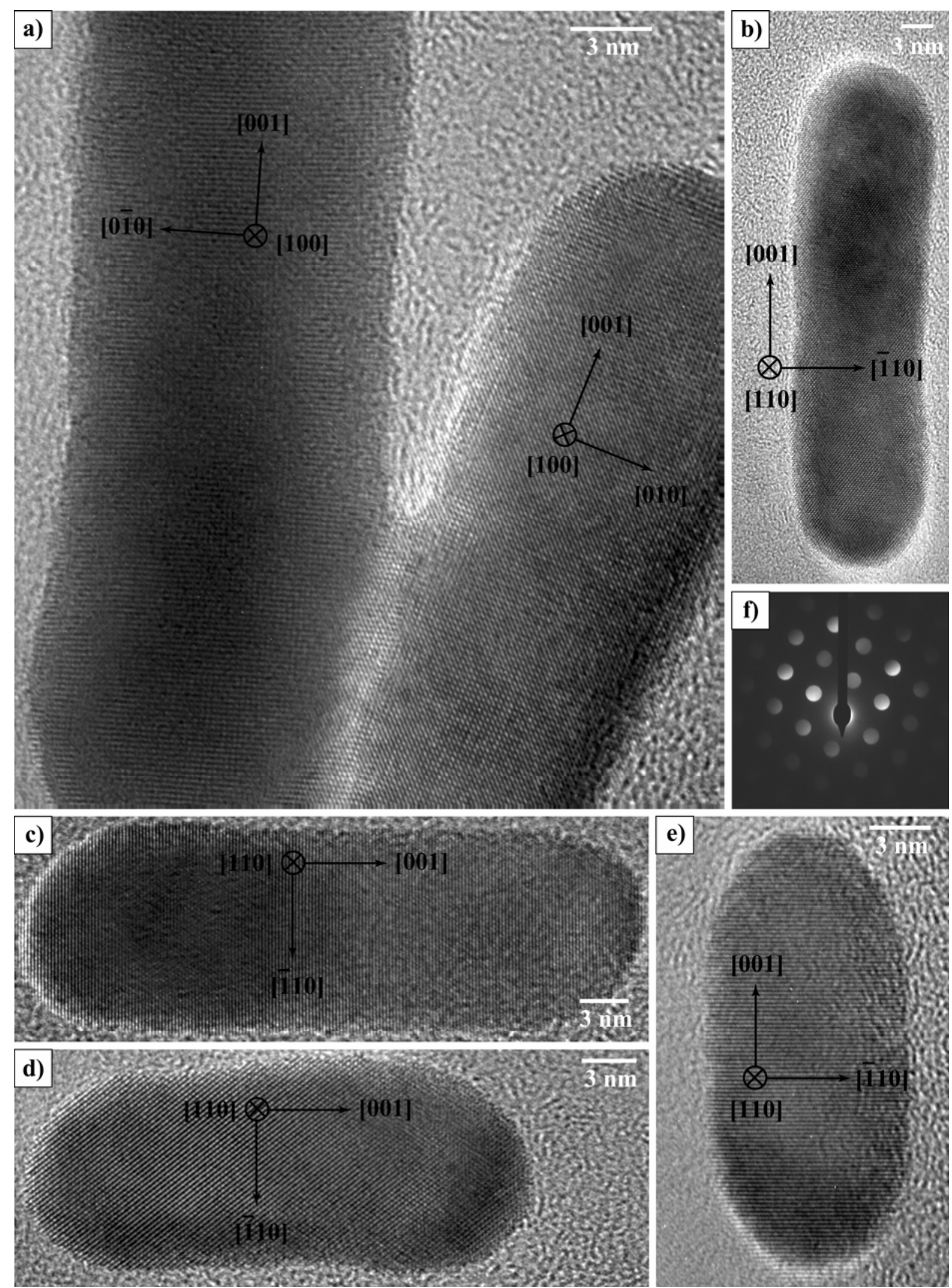

Figure S4. HRTEM characterization of Au NRs. (a) Two NRs oriented in the [100] direction. (b), 
(c), (d), and (e) NRs oriented in the [110] direction. (f) Electron diffraction pattern taken on a single Au NR oriented along the [110] zone axis. The aspect ratios of the Au NRs shown in (b), (c), (d), and (e) are 3.8, 3.1, 2.5, and 2.2, respectively. 